\title{
EL MITO GRIEGO COMO FUENTE DE INSPIRACIÓN DE LA LEYENDA DE TRISTÁN E ISOLDA, EN UNOS APUNTES INÉDITOS DE F. DE SAUSSURE: POCRIS, HIPÓLITO Y ENONE
}

\author{
Montserrat Morales Peco \\ Universidad de Castilla-La Mancha
}

\section{RESUMEN}

Saussure trata de demostrar el origen mitológico de la historia de Tristán e Isolda. El mito aporta ciertos elementos invariables que han perdurado en la leyenda céltica, aunque bajo formas, en ocasiones, distintas. Entre las transformaciones que pueden experimentar los contenidos míticos de un estado de leyenda a otro, se encuentra la reducción o atenuación, en las propias palabras del linguiista. El método comparativo le lleva a deducir los temas y motivos comunes entre Procris, Hipólito y Enone, por un lado, y la leyenda de Tristán, por otro. Cuando encuentra algún cambio trata de imaginar y recomponer el estadio primitivo de la leyenda y de explicar su evolución al actual.

El célebre lingüista suizo, con motivo de la preparación de un curso sobre literaturas germánicas en la universidad de Ginebra, inició un profundo e interesante estudio acerca del origen y desarrollo de la leyenda, que, aunque no llegó a publicar, se ha conservado en forma de apuntes manuscritos ' que debió escribir hacia 1903.

\footnotetext{
1 Algunos párrafos de estos manuscritos, aunque no todos los que hemos consultado para el presente trabajo, han sido editados por MARINETTI y MELI, Ferdinand de Saussure. Le leggende germaniche, Este, Zielo, 1986.
} 
Si bien considera que la mayoría de las leyendas germánicas, como los ciclos de los nibelungos y de Teodorico de Verona, tienen un origen histórico, otras, como la leyenda céltica de Tristán e Isolda, presentan una base exclusivamente mitológica.

A este respecto, Saussure creía en una posible circulación, durante el Imperio Romano, de los mitos greco-latinos por el Norte de Europa, de ahí el papel importante que desempeñaron en la elaboración de la leyenda.

Pues bien, nos proponemos como objetivo en el presente artículo analizar una parte de estos manuscritos de Saussure referentes al origen de la leyenda de Tristán e Isolda.

Saussure defiende que bastantes episodios de esta leyenda presentan la huella indeleble de varios mitos griegos. El mito de Teseo, que será objeto de otro estudio, habría influido principalmente en la formación de su vertiente épica, mientras Procris, Hipólito y Enone, mitos que nos ocupan ahora, habrían contribuido a configurar su vertiente erótica. Si bien el primero gravitaba en torno a la figura de Tristán y sus proezas, estos otros giran, fundamentalmente, en torno al personaje de Isolda y a la historia de amor.

\section{El MITO DE PROCRIS}

Del análisis contrastivo que Saussure efectúa del mito de Procris y de la leyenda de Tristán e Isolda podemos deducir la existencia de ciertos temas y motivos comunes.

1. Infidelidad de la esposa: Procris engaña a su marido Céfalo con Pteleón ${ }^{2}$, así como Isolda a Marke con Tristán.

2. Trampa del marido para descubrir el adulterio: Céfalo, dudando de la fidelidad de su esposa, decidió un día ponerla a prueba. Disfrazado de otro hombre, ofreció regalos cada vez más valiosos a Procris para que se le entregara. Procris, no pudiendo resistir la tentación, acabó cediendo y entonces Céfalo se dió a conocer ${ }^{3}$. A su vez, el rey Marke, ayudado por el enano, ideó

2 Cf. Apolodoro, III 15.

${ }^{3}$ Este tema del mito de Procris considerado por Saussure se encuentra únicamente en la versión de Ovidio: «Decido, para mi pesar, investigar y tentar con regalos su casta fidelidad; la Aurora secunda mis temores y cambia mi figura (me pareció advertirlo). Así, irreconocible, entro en Atenas, grata a Palas, y penetro en mi casa $/ . . . /$ hasta que hablando de darle dinero por una noche y al aumentar los regalos, al fin la hice dudar, en mala hora victorioso, grito: "Por desgracia tienes ante ti un falso amante. ¡Era yo, tu verdadero marido! Estás cogida, pérfida, y soy tu testigo! "” (Metamorfosis, libro VII, vv. 720-743). Y también en Higino, Fabulae 189 (ed. por Muncker), cuyo tex to aparece copiado por Saussure en el cuaderno 3959.10.2. 
esparcir harina en torno a la cama de Isolda para que, al acercarse Tristán a la misma, la huella de sus pies quedara marcada. Tristán, avisado de la trampa, se vio obligado a saltar para alcanzar la cama de Isolda, pero del esfuerzo una de sus heridas se abrió y manchó las sábanas de la amada, señal indeleble de adulterio ${ }^{4}$.

3. Rapto de la esposa.

a) Por un hombre extranjero, proveniente de ultramar: en el caso de Procris parece que no existe tal rapto si nos atenemos a la versión más conocida de esta fábula griega, según la cual la mujer de Céfalo, avergonzada de su comportamiento, huye a Creta, donde se convierte en la amante de Minos, rey de esta isla ${ }^{5}$. Sin embargo, Saussure supone que esta versión podría proceder de una "medio-transformación» de la fábula primitiva, según la cual Minos, aprovechando que Céfalo habría dejado de proteger a su esposa, como consecuencia de la falta cometida, la rapta y se la lleva a su isla. Respecto a una de las versiones, la de Gottfried de Strasbourg, de la leyenda de Tristán, un barón de Irlanda, músico de cítara, llamado Gandín (en la Saga noruega se habla de un arpista irlandés anónimo ${ }^{6}$ ), rapta a Isolda de una forma bastante cómica, pidiendo a Marke, a cambio de sus servicios como instrumentista, que le entregue a Isolda con quien pretende volver a su país?

b) Por un hombre que padece una enfermedad repugnante, como medio de agravar el suplicio de la esposa infiel: Minos se hallaba bajo los efectos de una maldición de su esposa Pasífae, a causa de la cual cuando se unía a otra mujer salían de su cuerpo serpientes y escorpiones, que mataban a la amante ${ }^{8}$. En el caso de la leyenda de Tristán, el raptor, según algunas versiones, es un conde leproso (Béroul ${ }^{9}$ y Eilhart d'Oberg ${ }^{10}$ ), aunque, según otras, carece de cualquier tipo de enfermedad repugnante, como en el caso de la versión de Gottfried o de la Saga noruega, donde es simplemente, según acabamos de ver, un músico. Sin embargo, Saussure supone que el personaje del leproso es evidentemente anterior y que el episodio del rapto con el instrumento es más bien

${ }^{4} \mathrm{Cf}$. Gottfried de Strasbourg, Tristan et Isolde, en Tristan et Yseut. Les premières versions européennes, Gallimard. 1995. pp. 581-583. BÉROUl, Tristan et Yseut, en Op. cit. pp. 20-21 (vv.643-770).

"Parece ser la versión de Ovidio: «vencida por su callada vergüenza. huyó de su traicionera casa y de su mal esposo» (Metamorfosis, VII, vv. 743-744).

' Frère Robert, La Saga de Tristram et dlsönd, en op. cit., pp. 853-854.

' Gottfried de Strasbourg, Op. cit., págs. 556- 558.

* Cf. ApOLODORO, 11115.

"Este conde leproso se llama Yvain en la versión de Béroul (Cf. vv. 1156-1229).

11) Tristrant, en Op, cit. p. 320. 
un añadido, pues se presenta dentro del relato sin ninguna conexión lógica con lo que precede y resulta tan poco realista como una farsa cómica.

Ahora bien, la leyenda de Tristán e Isolda introduce una variante notable con respecto al mito griego que le ha servido de fuente de inspiración. El rapto de Procris resulta efectivo, pero no podemos decir lo mismo del de Isolda que fracasa gracias a la intervención de Tristán para liberarla. Según Saussure se trata de un nuevo elemento insertado en la fábula originaria como evidencia el que, durante esta escena del rapto, Tristán se halle oculto a los ojos de los personajes que participan activamente en la acción:

$<$ Mark> L'époux outragé, consent, et la malheureuse est <livrée>. C'est à ce moment que Tristan, <jusque là> caché à tous les yeux -et qui en effet $n$ 'avait rien à faire $<$ du tout $>$ dans la scène primitive- se met à la poursuite de l'infâme, qu'il pourfend de son épée [...] (3959.8.3v-4r $\left.{ }^{11}\right)$.

On voit souvent dans la coulisse les personnages qui n'appartenaient pas primitivement à <l' action>. Dans Gottfrid Tristan est absent aussi au moment où Marke livre Isolt à l'étranger (Ibid.).

Asimismo, la supervivencia de uno de los acompañantes del raptor ${ }^{12} \mathrm{o}$ la suya propia ${ }^{13}$ constituye una huella de la versión originaria más cercana al mito de Procris, según la cual el raptor se llevaría a su víctima al otro lado del mar:

[ ... ] Lui et sa troupe de lépreux est détruite à l'exception d'un seul <qui s'en retourne chez lui>. Ce survivant est là en souvenir de la version originaire, où le duc emportait bel et bien sa victime de l'autre côté de la mer. Dans Gottfrid le ravisseur n'est pas tué, retourne en Irlande quoique sans Isolt (lbid.).

4. Regreso de la esposa, disfrazada de hombre, y vida en el bosque o en plena naturaleza junto a su marido, convertida en su compañero de caza (3959.8.4v-5r): según la versión que Saussure sigue del mito griego, Procris, tras su estancia en Creta, vuelve al Ática con una indumentaria masculina, de forma

1 Estas referencias corresponden a las signaturas con las que se han inventariado los manuscritos de Saussure en la Biblioteca Pública y Universitaria de Ginebra.

12 Cf. Ellhart d'OberG, Op. cit., p. 321.

1.3 Les auteurs disent qu'ils ont fait tuer Yvain; ils ne connaissent pas bien cette histoire. Béroul s'en souvient mieux, car Tristan est bien trop noble et courtois pour occire des gens de cette sorte» (BEROUL, op. cit., pp. 36-37, vv. 1265-1270). 
que nadie la reconoce. Pasa a ser el compañero de caza de Céfalo, que habita lejos de Atenas en la aldea de Thorikós o en otro lugar de caza cualquiera ${ }^{14}$.

La leyenda de Tristán e Isolda repite este motivo mítico. Isolda, tras ser liberada del duque leproso, huye con Tristán al bosque de Morrois y allí viven únicamente de la caza ${ }^{15}$.

Aunque introduce también algunas variantes. En primer lugar, aparece un personaje nuevo, Governal, que acompaña a la pareja en su huida al bosque, pero o bien vive distante de ellos ${ }^{16}$ o bien el narrador de vez en cuando deja de referirse a él ${ }^{17}$, lo que indica, en opinión de Saussure, que dicho personaje no figurara primitivamente en este episodio, en la versión originaria de la leyenda, y resulte más bien un añadido posterior.

Por otra parte, si bien antes el personaje de Tristán, que mata al leproso o rescata a Isolda de manos del barón músico irlandés, era una invención añadida al motivo originario del rapto de la adúltera, es a partir de este episodio cuando funciona en realidad en la versión tradicional de la leyenda. Céfalo, que, como marido engañado poniendo a prueba la fidelidad de su esposa, se identificaba con Marke, ahora en su función de cazador, que vive en lo más recóndito del bosque, se encarna en Tristán. Cierta variente, al respecto, se encuentra en la novela de Gottfried de Strasbourg. Si bien, Gottfried se niega a presentar a Tristán bajo la figura de un cazador en la Minnegrotte (gruta de amor), especificando que el único alimento que mantenía vivos a los amantes era su amor mutuo, no obstante reconoce que el motivo de la caza se encuentra en bastantes fábulas sobre Tristán:

Nombreux sont ceux qui racontent des sotties et des absurdités, et je ne les suivrai pas: ils disent qu'il faut à ce genre d'occupation bien d'autre nourriture. Je ne sais pas ci c'est vrai: il me semble que cela leur suffisait. Mais s'il devait se trouver quelqu'un qui a connu dans cette vie meilleure nourriture, qu'il dise ce qu'il en connaît. Il m'est arrivé aussi de mener ce genre de vie et j'e n'avais besoin de rien d'autre ${ }^{18}$.

14 Véase Higino, Fabulae 189, texto copiado por Saussure en 3959.10.2.

${ }^{15}$ Bosque situado en Cornualles que se identifica generalmente con la casa de campo de $\mathrm{Mo}$ resc o Saint-Clement's, cerca de Truro.

it En la novela de Eilhart d'Oberg, no comparte la cabaña con los amantes, a deducir de las palabras de Tristán: «Tristrant dit alors à Isald de courir chercher Kunerwal... » (Op. cit., p. 325).

17 En la versión de Gottfried de Strasbourg, una vez que los amantes se instalan en la cueva de amor el narrador deja de hablar súbitamente de Curneval, hasta que poco después refiere que los amantes lo envían de regreso a la corte (Cf. Op. cit., pp. 600-601).

${ }^{18}$ GotTfried de Strasbourg, Op. cit., p. 603. 
Y, aunque Gottfried acabe finalmente reconociendo que los amantes se dedicaron a la caza, sigue insistiendo que lo hacían no con la intención de obtener alimento, sino simplemente por diversión ${ }^{19}$.

Finalmente, Isolda no aparece en ninguna versión disfrazada de hombre, como Procris. No obstante, según Saussure, quizás el nombre mismo de Minnegrotte sea el indicio de que la amada de Tristán representa a una heroína que ha adquirido ciertas cualidades del sexo opuesto. En efecto, minne recuerda el código cortés de la fine amor (que de los trovadores del sur de Francia se difundió a las novelas en langue d'oül y a la poesía alemana), en función del cual la mujer amada se convierte en todo un señor feudal, con un poder en ocasiones cruel y humillante, al que se somete el amante en calidad de vasallo.

Además, cuando los amantes son sorprendidos en el lecho de amor, una espada separa sus cuerpos. Este motivo vendría a indicar, en opinión de Saussure, que Tristán e Isolda, al igual que Céfalo y Procris, no se comportan en el bosque como dos amantes, a pesar de los lazos que los unían anteriormente, lo que quizás sea un resto del motivo primitivo del disfraz masculino de la esposa. Respecto de este valor simbólico Saussure comenta, en otro lugar, una fórmula empleada por Gottfried en la descripción de esta escena de la espada, que presenta a la pareja como dos hombres y no como un hombre y una mujer, durante su estancia en el bosque:

si giengen an ir bette wider und leiten sich dâ wider nider von ein ander wol hin dan reht'alse man unde man niht alse man und wîp "i"

Emploi pour indiquer la pureté d'une formule qui avait pu signifier toute autre chose (Mais même si on ne rapporte plus la formule à la scène en question, reste importante au point de vue de la cohabitation pendant l'ensemble de leur séjour où ils étaient comme 2 compagnons de chasse, Procris étant un homme pour son compagnon)» (3959.10.14).

5. El perro con el que regresa la esposa (3959.8.5v-6r): el mito griego cuenta que Procris trajo consigo de Creta un perro fabuloso, de bronce, llamado Lélaps, al que ningún animal de caza podía escapar. Zeus lo había convertido

14 Gotthried de Strasbourg, Op. cit., p. 607.

21" «lls retournèrent à leur couche et s'y allongèrent à nouveau, mais ils s'écartèrent l'un de l'autre, comme seraient couchés deux hommes, et non pas un couple d'amants» (GoTTFRIED DF: STRASBOURG, Op. cit., p. 609). 
en guardián de Europa y ésta lo entregó luego a su hijo Minos, quien, finalmente, lo regaló a Procris como recompensa por haberle curado de la enfermedad de Pasífae ${ }^{21}$.

Este motivo ocupa también un primer plano en la historia de la Minnegrotte. Tras la huida de Tristán e Isolda, el rey Marke ordena ahorcar al perro favorito de Tristán, Husdent. Sin embargo, éste logra escapar y se reúne con la pareja en el bosque $^{22}$. En otras versiones, junto a Husdent aparece otro perro encantado, que Tristán recibió como premio de su victoria sobre un gigante. Este perro recibe el nombre de Petit-Crû ${ }^{23}$. En la Saga noruega, ambos perros se presentan como el mismo, de lo que se deduce que la huida de los amantes al bosque tiene lugar después de un primer exilio de Tristán, durante el cual tuvo ocasión de conquistar al animal ${ }^{24}$. En cambio, Gottfried, a pesar de seguir la misma versión de la Saga noruega, en su novela precisa que se trata de perros distintos. El primero en aparecer en su relato es Petit-Crû. Tristán lo había recibido del duque Guilán de Swales (un duque de Polonia, en la Saga) por haber derrotado al gigante Urgán el Velludo que mantenía sometido a su pueblo, y lo envió a Isolda en señal de amor ${ }^{25}$. Después, con motivo de la fuga de los amantes a la Minnegrotte, el narrador menciona a uno de los perros de caza de Tristán, llamado Hiudán ${ }^{26}$.

De las aclaraciones de Saussure en el cuaderno $n .^{\circ} 10$, podemos deducir que el mítico Lélaps se desdobla en dos tipos diferentes de perro: por una parte, en un simple perro de caza, fiel a su amo Tristán, que acompaña a los enamorados en el bosque y que su dueño enseña a no ladrar; $y$, por otra, en el perro encantado que Tristán regala a Isolda como prueba de amor, cuando está lejos de ella, en el exilio, para que su amada manifieste a este animal el amor que le profesa a él (3959. 10.1).

21 Esta versión del mito de Procris, es la que refiere Higino en su obra Poeticon Astronomicon, II, 35 (editado por Muncker con el título Auctores Mythographi Latini: C. Jul. Hyginus, Fab., Planc. Fulgentius, Lactantius Placidius, Albrichus Philosophus, 1742), que Saussure ha consultado. Véase. a este respecto, 3959. 10.1 de los manuscritos de Saussure. Sin embargo, para Ovidio. el perro como la jabalina lo recibió Procris de Diana, dado que en esta versión el episodio de Minos es sustituido por la huida de Procris al bosque de Diana (Metamorfosis, VIl, vv. 745-756).

22 Cf. BÉROUL, Op. cit. pp. 41-46 (vv. 1437-1635).

2. Folie Tristan d'Oxford, en Op. cit., pp. 236-237 (vv.758-761).

24 "C'est de la sorte que ce chien fut obtenu et acquis. Je veux maintenant que vous sachiez que le chien de Tristram ne resta pas longtemps à la cour du roi Markis. Par la suite, il prit l'habitude d'aller dans les forêts chasser le sanglier et le cerf lorsque Tristram et Isönd se trouvaient là tous les deux» (Frère ROBERT, Op. cit., p. 876).

2. GotTFried de STRAsbolirg, Op. cit., pp. 594-596.

2h «Il avait enfin choisi un chien de chasse, à la fois beau et fin, qui s'appelait Hiudan: il le prit lui-même par la longe $\mid$... I, et il prit lui-même l'arbalète, le cor et le chien aussi. Hiudan, pas Petitcreiu» (GotTFried de Strashourg, Op. cit., pp. 599-600). 
Tras haber analizado las referencias de Higino a Lélaps en Poeticon Astronomicon (3959.10.1) y en Fabulae (3959.10.2), y haberlas contrastado con la historia de Petit-Crû, Saussure extrae algunos motivos comunes a ambos, lo que le sirve de prueba irrefutable de la influencia de esta fábula mitológica en el origen de la leyenda de Tristán e Isolda:

Petitcriu:

1. Vient d'une gotinne.

2. ${ }^{\circ}$ Est merveilleux, - V. Preller où il est aussi merveilleux comme corps, ayant été fait avec du bronze.

3. Passe, depuis la gotinne, aux mains de deux hommes et une femme, et est un chien qui a la spécialité de servir de présent.

4. Il est spécialement donné à une femme (Procris-lsolt) par celui qu'elle a guéri (Minos-Tristan).

5. Il passe d'un amant à l'autre: Procris-Céphale.

$6{ }^{\circ}$ On offre avec insistance la moitié du royaume.

7. Arrive à la fin dans le pays de Marke, venant d'un pays étranger (3959.10.1).

En efecto, el perro procede de una diosa. En Gottfried de Strasbourg, Petit-Crû proviene de Avalon, país de las hadas. Una diosa lo regaló a Guilán en señal de amor ${ }^{27}$. En Ovidio y en Higino, el perro es también ofrecido por una diosa, en este caso Diana ${ }^{28}$ y, según el Poeticon Astronomicon de Higino, otro dios, Júpiter, lo entregó a Europa y ésta a Minos ${ }^{29}$.

Es un animal mágico. A Lélaps ninguna fiera puede superarle ${ }^{30}$. En Gottfried el encanto fabuloso de Petit-Crû radica en su cascabel que hace olvidar las penas causadas por el amor y en su pelo policromático ${ }^{31}$.

Tras haber sido propiedad de una diosa, llega a pertenecer a dos hombres y luego a una mujer. De Júpiter y Minos, Lélaps pasa a Procris. Asimismo, de Guilán y Tristán Petit-Crû pasa a Isolda.

Es ofrecido por un hombre enfermo a la mujer que lo ha sanado. Minos regala Lélaps a Procris por haber roto el hechizo del que era víctima. Del mismo modo, Tristán regala Petit-Crû a la mujer que lo libró del envenenamiento.

${ }^{27}$ Cf. Op. cit., p. 589.

${ }^{28}$ Cf. Metamorfosis, libro VII, vv. 746-754 y Fabulae, 189 (texto citado por Saussure en el cuaderno 3959.10.2).

${ }^{29} \mathrm{Cit}$. por Saussure en 3959. 10. 1.

4) Ovidio, Metamofosis, VII, v. 755; Higino, Poeticon Astronomicon, 1135 (cit. por Saussure en 3959. 10. 1); Higino, Fabulae 189 (cit. por Saussure en 3959.10.2).

${ }^{3}$ Cf. Op. cit., pp. 589-590. 
Pasa de un amante al otro. De Procris a Céfalo y de Tristán a Isolda.

El dueño del perro ofrece con insistencia, en vez del animal mágico, la mitad de sus posesiones. En la fábula 189 de Higino, que Saussure consulta, se nos cuenta que Céfalo, habiendo quedado fascinado por el poder del perro y de la jabalina de Procris (ésta se había disfrazado de hombre y rivalizaba en la caza con Céfalo), le llegó a proponer una parte de su reino a cambio de aquéllos, pero Procris se negó a venderlos (3959.10.2). Asimismo, según algunas versiones de la leyenda céltica, por ejemplo, en Gottfried, Tristán rechaza a Guilán cuanto quiere ofrecerle en lugar del perro:

Le duc dit alors: «J'aurais une meilleure proposition à vous faire! —Dites toujours! reprit Tristan. —Laissez-moi le petit chien! Acceptez à la place la main de ma jolie soeur, avec en outre la moitié de tout ce que je possède. -Non, seigneur duc Gilan, rappelez-vous votre promesse: si j'avais le choix, je n'accepterais pas en échange de votre chien tous les royaurnes et toutes les terres du monde. Ce n'est que pour avoir Petitcreiu que j'ai tué Urgan le Velu! [...]» ${ }^{32}$.

Por último, Saussure piensa que la fábula del perro de Céfalo ha encontrado una importante acogida en la leyenda de Tristán no sólo porque concierne a una historia de amor, sino también precisamente porque es «ático-cretense», al igual que el mito que más ha influido en Tristán, Teseo. De Creta, país de Procris, según cierta tradición (Procris aparece, en la Odisea, junto a las hijas de Minos, Ariadna y Fedra, como comprueba Saussure), Lélaps pasa ulteriormente al Ática, país de Céfalo, su esposo. La historia de Petit-Crû presenta la misma evolución espacial: de un país extranjero, Swales o Polonia ${ }^{33}$, a Cornualles (3959. 10. 1), país de Marke, su esposo.

Aparte de estos motivos principales existen otros elementos que acercan la leyenda de Tristán e Isolda al mito de Procris.

La mujer sana al enemigo. Procris salva a Minos, rival tradicional del rey de Atenas, del encantamiento de Pasífae, gracias a una hierba que había recibido de Circe. Según Apolodoro además de curandera es amante ${ }^{34}$. Asimismo, Isolda no sólo cura las heridas del guerrero que mató a su tío Moroldo (3959.8. lr), sino que también se convierte en su amante.

32 Gottfried de Strasbourg, Op. cit., p. 594.

3. Asimismo en la novela de Gottfried de Strasbourg. Isolda cuenta a Marke que Petit-Crâ proviene de Irlanda y es un regalo de su madre: «... c'était sa mère, la sage reine d'lrlande, qui le lui avait envoyé» (Op. cit., p. 595).

34 Apolodoro 115. 
Respecto al espía de la unión ilícita, Saussure sospecha que en el origen de Auctrat (Antret, en Tristrant de Eilhart d'Oberg), delator del adulterio de Tristán et Isolda, se puede encontrar un personaje anónimo de las Metamorfo. sis de Ovidio, que confudiendo a la Brisa, a la que invoca el cazador Céfalo en el monte, con una ninfa, denuncia la supuesta culpa a Procris. Para demostrar esta hipótesis Saussure parte del texto original latino del libro VII de las Metamorfosis $y$, en concreto, de dos versos, el 824 y el 825 :

Criminis extemplo ficti temerarius auctor Procrin adit, linguaque refert audita susurra ${ }^{35}$.

Según Saussure, Auctrat podría provenir de haber tomado «auctor» (delator del crimen) como un nombre propio. Después la sintaxis de la frase pudo experimentar algún cambio: el temerario Auctor «va a dar parte del crimen a Procris» («adit Procrin criminis») o quizás, por el contrario, debido a una mala lectura o a la ambigüedad misma de la expresión, «acusa a Procris de un crimen». Por último, se pregunta si con el paso del tiempo el «temerarius Auctor» pasó a leerse «camerarius Auctor» (el chambelán Auctor) (3959.8.2r-lv).

Asimismo, también encuentra ciertas similitudes entre la escena del espionaje de Procris y la escena del matorral, en la que son sorprendidos Tristán et Isolda:

Par certains côtés le rendez-vous surpris rappelle la scène du buisson de Procris.

Auctrat est l'instigateur, quoique absent, mais il est absent <aussi $>$ dans la scène de Tristan de la fin.

Il y a cachette dans le feuillage.

Il y a emploi d'un rîs, à fendre en long. <et qui va de Tristan à lsolt Tristan lance un Reiss vers Isolt dans la scène de la fin $(3959.8 .2 \mathrm{v})$.

\section{Los MITOS DE Hipólito y ENONE}

Aparte de Procris y Céfalo, otros mitos griegos inspiran la vertiente idílica de la leyenda de Tristán e Isolda, como Hipólito y Fedra o Enone y Paris. Saussure establece un cuadro sinóptico con los temas y motivos que todos es-

39 «Al punto, este imprudente delator de una culpa supuesta / Corre a ver a Procris y entre susurros le cuenta lo oído", según la traducción de Antonio Ramírez de Verger y Fernando Navarro Antolín (Ovidio, Metamorfosis, Madrid, Alianza Editorial, 1996, p. 236). 
tos mitos han podido aportar a la leyenda. Por otra parte, observa que las correspondencias también se establecen entre sí. Asimismo, hay que destacar que en este cuadro sinóptico Teseo presenta un valor cero:

\begin{tabular}{ccccc}
\hline & Thésée & Hippolyte & Céphale & Paris \\
\hline Chasseur & - & Chasseur & Chasseur & \\
\hline Femme guérissante & - & - & Procris & Oenone \\
\hline Chasseresse & & (Phèdre) & Procris & - \\
\hline $\begin{array}{c}\text { Amour fatal par issue } \\
\text { Jalousie }\end{array}$ & - & $\begin{array}{c}\text { Phèdre } \\
\text { Hippolyte }\end{array}$ & Procris & $\begin{array}{c}\text { Enone } \\
\text { Paris }\end{array}$ \\
\hline $\begin{array}{c}\text { Amour tendre malgré } \\
\text { jalousie }\end{array}$ & - & (Phèdre) & Procris & Oenone \\
\hline $\begin{array}{c}\text { <eau->Fils aimé de } \\
\text { sa belle-mère }\end{array}$ & - & $\begin{array}{c}\text { Phèdre à } \\
\text { Hippolyte } \\
\text { Thésée }\end{array}$ & - & $\begin{array}{c}\text { Hélène- } \\
\text { Cxil }\end{array}$ \\
\hline
\end{tabular}

Fedra y su gran amado Hipólito componen, al igual que Tristán e Isolda, una pareja de cazadores. Hipólito, hijo de Teseo, había heredado de su madre, una amazona, la pasión por la caza y las prácticas violentas. Y entre todas las divinidades, distinguía con especial veneración a Ártemis. No obstante, respecto de Fedra, no todos los mitógrafos la presentan como una cazadora, de ahí el empleo por Saussure de los paréntesis. En cambio, esta tan peculiar imagen de la esposa de Teseo se encuentra en las Heroidas de Ovidio, que Saussure, sin duda, ha consultado para su estudio: "Ya incluso -apenas lo creerás- me siento inclinada a actividades desacostumbradas: siento el afán de ir por medio de las fieras salvajes; ya es la primera para mí la diosa Delos, que se destaca por su curvo arco; también yo sigo tu afición [... ]» ${ }^{36}$.

El amor que une Fedra a Hipólito, Procris a Céfalo y Enone a Paris resulta también, como en el caso de la leyenda céltica, fatal, sin otra salida que la

3t OvIDIo, Heroidas IV. 
muerte. Ciertamente, Hipólito muere presa de sus propios caballos, por haber rechazado a Fedra, quien, a su vez, se ahorca:

[ ... ], y le pidió que se uniese a ella, pero como éste odiaba a todas las mujeres, rehuyó el encuentro. Fedra, temiendo que la acusara ante su padre, forzó las puertas de su alcoba, desgarró sus vestidos y acusó a Hipólito de atropello. Teseo la creyó y suplicó a Posidón que Hipólito pereciese. Así, cuando éste corría guiando su carro cerca del mar, Posidón hizo surgir del oleaje un toro y al espantarse los caballos el carro se estrelló. Hipólito, enredado con las riendas, murió arrastrado. Fedra, al hacerse manifiesta su pasión, se ahorcó ${ }^{37}$.

Asimismo, Procris, sospechando de su marido, quien se marchaba de caza con excesiva frecuencia, decidió seguirlo un día; pero él, oyendo moverse un matorral, disparó en su dirección una jabalina, con lo que Procris cayó mortalmente ${ }^{38}$. Enone, a quien Paris abandonó por Helena, se negó, por despecho, a curarle una herida de flecha, de modo que Paris murió. Sin embargo, ella no tardó en arrepentirse de su crueldad y acudió con sus remedios, esperando encontrar aún vivo a su antiguo amante. Al saber que había muerto, se suicidó ahorcándose o arrojándose a la pira funeraria.

Tanto Fedra como Procris o Enone encarnan la imagen de la mujer celosa y, a pesar de ello, amante tierna y fiel, atormentada por el abandono, la lejanía y la infidelidad del amado. A este respecto, todas ellas recuerdan los celos y sufrimientos de Isolda, a causa del exilio de Tristán en Bretaña y de su matrimonio con otra mujer, Isolda de las Blancas Manos.

Asimismo, en los mitos de Fedra y Enone encontramos la misma situación de triángulo amoroso que en la leyenda de Tristán e Isolda, integrado por el padre, la madrastra y el hijastro amado. En efecto, Fedra ama al hijo de su marido Teseo, Hipólito, y Helena se enamora de Córito, hijo de Paris y Enone.

Por otra parte, además de Procris, Enone también figura a la mujer curandera. Este don lo recibe de Apolo, que se enamoró de ella: «Se ha enamorado de mí el constructor de las murallas de Troya, famoso por su lira. Él tiene el trofeo de mi virginidad, y eso incluso luchando [ ... ]. Y no he pedido joyas ni oro como precio por la violación, es vergonzoso que un cuerpo libre lo compren los regalos. Él mismo, considerándome idónea para ello, me enseñó las artes de la medicina y permitió que mis manos accedieran a sus dones. Cualquier

${ }^{37}$ A POLODORO, Epítome 18 y 19. El episodio de la muerte de Hipólito se refiere también en Ovidio, Metamorfosis. VII, vv. 497-529.

${ }^{38}$ Ovidio, Metamorfosis, VII, vv. 794-862. 
hierba capaz de proporcionar algún alivio, y raíz de virtudes curativas que se críe en todo el mundo me es conocida» ${ }^{39}$.

Por último, el exilio de Tristán también parece recordar los de Hipólito y Céfalo. Hipólito, tras su muerte, es resucitado y transportado por la diosa Diana a su santuario de Aricia, en Italia, donde inicia una vida nueva, en el retiro, bajo el nombre de Virbio ${ }^{40}$. A su vez, Céfalo, una vez reconciliado con Procris, vive retirado en el monte, dedicándose a la caza. Asimismo, tras la muerte de su esposa, es condenado al eterno destierro ${ }^{41}$.

De este estudio comparativo Saussure deduce que en especial son los mitos de Céfalo e Hipólito los que presentan más correspondencias.

Según Saussure, la fusión entre Céfalo e Hipólito aparece facilitada por ciertos rasgos que presentan en común: los dos son príncipes atenienses, cazadores, víctimas de un amor trágico y relacionados con el ciclo Cretense (Céfalo de varias formas, pues independientemente de su historia con Procris, Ovidio lo representa en embajada a Egina, a fin de solicitar en nombre de Atenas ayuda en la lucha contra Creta, donde Nereo le hace relatar su vida (3959. 10.9) ${ }^{42}$.

Sin embargo, Saussure reconoce que algunos episodios de estos mitos han sido suprimidos en el poema de Tristán e Isolda, aunque dejando cierta huella en escenas atenuadas, salvo la muerte de Fedra:

1. Perte ou abandon d'Ariane.

2. Mort d'Hippolyte et <mort> de Phèdre.

3. Mort de Procris.

(4. Le bain de Minos, épisodique).

(5. Mort de Corythus? fils d'Oenone) (3959.8.1v).

Como Teseo, en su viaje de regreso de Creta a Atenas, pierde a Ariadna, al ser raptada por Dionisos, o la abandona, en la isla de Día o Naxos, así también Tristán, tras unirse a Isolda, la pierde en un lugar entre Irlanda e Inglaterra, al tener que entregarla a su tío Marke. Sin embargo, si bien en el mito de Teseo este abandono o pérdida es real y efectiva, no lo es en la leyenda céltica, pues Tristán e Isolda seguirán viéndose y amándose a escondidas en Cornualles.

\footnotetext{
${ }^{34}$ Ovidio, Heroidas, $V$.

4) Cf. Ovidio, Metamorfosis, XV, vv. 53l-546

${ }^{41} \mathrm{Cf}$. Apolodoro, $\mathrm{III} 15$.

42 Céfalo pide, en nombre del pueblo de Atenas, ayuda a esta isla en la batalla contra el rey
} de Creta, Minos, que quiere vengar la muerte de su hijo Androgeo (cf. Ovidio, Metamorfosis, Vll, vv. 494-516). 
La muerte de Hipólito, víctima de su cuádriga, se proyecta de forma atenuada en la escena ecuestre de Phelerin, que analizaremos a continuación.

El episodio de la muerte de Procris parece, también, emerger en la escena del encuentro secreto de los amantes, en la que uno de los barones de Marke, que había sorprendido a la pareja, resulta mortalmente alcanzado por la flecha de Tristán.

El baño de Minos parece tener eco en la escena del baño curativo que prepara Isolda a Tristán.

Por último, la proyección del motivo de la muerte de Córito en la leyenda de Tristán no ha sido aclarada por Saussure. De lo que podemos pensar que ha debido de suprimirlo finalmente.

Según Saussure, el que se hayan eliminado algunos episodios de estos mitos y se encuentren atenuados otros se debe a la obligación de fusionar estos personajes mitológicos y de entrelazar sus diferentes historias. Luego se podría afirmar que los rasgos de estos mitos que han influido en la génesis de la leyenda de Tristán e Isolda son únicamente aquellos en los que todos, o algunos, coinciden y que Saussure ha expuesto en el cuadro anterior.

La fuente principal de información, consultada por Saussure para su estudio sobre el mito de Hipólito y Fedra, es esencialmente el libro IV de la $B i$ blioteca histórica de Diodoro de Siculo (3959.10.10).

En principio, Hipólito recuerda a Tristán, como también a Teseo, en lo concerniente a su formación en el extranjero, lejos de su padre. Tras su matrimonio con Fedra, Teseo envía a Trecén a su hijo ilegítimo Hipólito, donde crece y se educa junto a los hermanos de Etra. Este tema recuerda, para Saussure, la formación de Tristán en casa de Rual como un miembro más de su familia, sin distinción especial ${ }^{4.3}$ (3959.10.10).

Pero, sin duda, en lo que más ha influido el mito de Hipólito en la leyenda de Tristán es, precisamente, en la temática del amor.

El amor pasional que expresa Isolda en ausencia de su amado recuerda los ruegos y los suspiros de amor que lanza Fedra a Hipólito, tras su partida, desde un templo en honor a Venus, que ella misma mandó construir en Atenas, y desde el cual podía vislumbrar Trecén (3959.10.10).

Asimismo, el episodio de los caballos de Hipólito, que, amedrentados por el enojo en el que le sumió la calumnia de Fedra, causaron su muerte, se proyecta en la escena ecuestre de la persecución de Phelerin (3959.10.12), tal y como aparece relatada en el Tristrant de Eilhart d'Oberg. Ciertamente, el episodio de la muerte de Hipólito, víctima de su propia cuadriga, se presenta de una

${ }^{43}$ CL Gottraied de Strasbourg, Op. cit., pp. 413-418. 
forma atenuada, como ya indicamos anteriormente, en la leyenda céltica, ya que los caballos dejan de ser causa de muerte para funcionar como meros agentes destructivos de la imagen de un Tristán héroe y amante.

Mientras Tristán y su compañero Kehenis, recién llegados de Bretaña, marchan al encuentro de Isolda, unos escuderos guardan sus caballos y sus armas en un lugar secreto. Sin embargo, son descubiertos por el caballero Phelerin que, confudiéndolos con sus señores, arremete contra ellos. Entonces, los escuderos se dan a la fuga, mientras Phelerin les exhorta a detenerse en nombre de Isolda. Phelerin regresa a la corte y relata a Isolda este acto de cobardía de Tristán que resulta al mismo tiempo humillante para la amada, al haberse negado el héroe a hacer frente en su nombre a Phelerin: «[ ... ] Comme il fuyait toujours à grande allure, je l'ai finalement exhorté à faire volte-face en invoquant votre nom; il a continué cependant à fuir à bride abattue, comme s'il n'avait rien entendu» ${ }^{44}$.

Uno de los restos de esta escena ecuestre en la novela de Tristán es precisamente el número de caballos que en ella intervienen. Son cuatro los caballos que se asuntan y matan a Hipólito (se nos habla siempre de una cuadriga). En el episodio de la persecución de Phelerin participan, en principio, sólo tres jinetes, con sus respectivos caballos, Kurnewal, el escudero de Kehenis y Phelerin, pero aparece y se habla con insistencia de otro caballo sin jinete, el de Tristán, que se pierde en el tumulto de la huida (3959.10.12):

Kurnewal arriva alors à son tour, en compagnie de l'écuyer de Kéhénis. Ils avaient trois chevaux en tout; ils avaient perdu le quatrième, au grand dépit et à la fureur de Kurnewal ${ }^{45}$.

Por otra parte, el nombre mismo de Phelerin, según Saussure, quizás proceda de la evolución de una palabra latina que designa un tipo especial de caballo, «palivrédus», la cual ha dado en francés moderno «palefroi», en español «palafrén» y en italiano «palafreno». Si fuera cierto, tendríamos la prueba de que el caballo que ha causado la muerte de Hipólito ha adquirido con el tiempo el estado de personaje (personaje lanzado en una persecución enloquecida contra Tristán o contra alguien que se cree es Tristán) (3959.8. retro copertina y 3959.10.14).

Ante el incidente del caballo perdido, Isolda reacciona, por vez primera, con desprecio e ironía contra Tristán, llegándole incluso a golpear y burlándose

44 EILHART D'Oberg, $O p$. cit., p. 353.

45 EILHART D'OBERG, Op. cit., p. 354. 
de él abiertamente, de tal forma que el héroe llega a sentir una profunda irritación. Es la escena en la que Tristán disfrazado de mendigo leproso busca hablar con Isolda y darle una explicación de la fuga de su caballo, que la amada interpreta como rechazo y prueba de cobardía ${ }^{46}$.

Ello se encuentra en estrecha relación con la crisis que provoca en Hipólito la calumnia de Fedra. Hipólito reacciona con indignación y esto, precisamente, lo distrae de su tiro y le provoca la muerte.

Por otra parte, la incredulidad que Isolda opone a la justificación de Tristán podría ser, en opinión de Saussure, una transposición de la incredulidad de Teseo a las explicaciones de su hijo (3959.10.12). Saussure pone de relieve a este respecto, la contradicción entre la manera como Isolda recibe primero a Phelerin (ante este hombre muestra su incredulidad acerca de la huida de Tristán) y el modo como recibe las explicaciones enviadas por Tristán (en cuyo caso cree que Tristán ha realmente huido sin querer detenerse ante la pronunciación de su nombre).

Otro resto atenuado de la muerte de Hipólito por Fedra se encuentra en el diálogo de Isolda con Phelerin (3959.10.12) en el que llega a decir:

Que ne l'as-tu emporté sur ton dos dans la mer, au moins je n'aurais plus jamais entendu parler de lui! ${ }^{47}$.

Isolda desea que Phelerin hubiera lanzado al mar a Tristán. Asimismo, Hipólito muere porque un monstruo marino, enviado por los dioses, quienes acabaron cediendo a las súplicas de Fedra, asusta a sus caballos.

Por otra parte, debido a la muerte ingrata de Hipólito y Fedra, fruto de una fatalidad o maldición, los trecenos les rindieron honores divinos, construyendo un templo, donde instalaron sus tumbas. Este motivo se refleja en el desenlace milagroso y divino que recibe la también trágica historia de amor entre Tristán e Isolda. Se dice que Marke recogió los dos cuerpos y los enterró en tumbas separadas, pero un rosal, plantado junto a la tumba de Tristán, creció hasta poder enredarse con una cepa que se elevaba de la de Isolda. Entonces Marke fundó un monasterio y mandó construir una catedral que cobijara en su interior las tumbas de los enamorados inseparables incluso en la muerte ${ }^{48}$ (3959. 10. 10).

Por último, Saussure piensa que la Minnegrotte, donde Tristán inicia una vida nueva y libre junto a su amada, puede tener su equivalente en el nuevo hogar que encuentra Hipólito, resucitado y transformado en Virbio (es decir

\footnotetext{
46 Eilhart d'OberG, Op. cit., pp. 355-356.

47 Eilhart d'Oberg, $O p$. cit., p. 353.

${ }^{4 *}$ Cf. URICH DE TURheim. Première continuation, en Op. cit., pp. 686-689.
} 
«dos veces hombre»), en el bosque sagrado de Diana, en compañía de la ninfa Egeria. Según Saussure, el texto de Gottfried de Strasbourg evidencia estas correspondencias. La descripción del espacio paradisíaco y selvático de la Minnegrotte recuerda el lugar de retiro de Hipólito-Virbio en el bosque de Diana, cerca de un lago, en medio de árboles y rodeado de rocas:

Mais en dessous il y avait tout à l'entour d'innombrables arbres qui, de leur feuillage et de leurs branches, donnaient de l'ombre au rocher. De l'autre côté s'étendait un vallon herbeux, où coulait une source fraîche et pure, aussi claire que la lumière du soleil [...]. Le rocher et la grotte étaient entourés, à une journée de voyage à la ronde au moins, de rochers sans cultures, de terres sauvages et désertiques ${ }^{49}$.

Por otra parte, Gottfried nos presenta a Isolda con los rasgos de una diosa y de una cazadora (3959.10.21):

-Oui, seigneur! Dans cette grotte il y a un homme et une déesse. Ils sont couchés sur un lit et dorment tous deux d'un profond sommeil. L'homme ressemble à tout autre homme.

Mais je ne peux pas croire que celle qui dort à côté de lui soit un être humain, car elle est plus belle qu'une fée $[\ldots]^{50}$.

[ ... ] ils partaient de temps à autre à cheval à travers bois, quand l'envie les en prenait, avec une arbalète, pour tirer les oiseaux et le gibier $^{51}$.

Todos los mitos hasta ahora comentados se entrelazan, según Saussure, en la leyenda de Tristán e Isolda del modo siguiente:

Jusqu'a mort de Morolt. -Exclusivement Thésée.

Isolt accourant près de Morolt. - Procris (Arianisé plus ou moins)

Tantris (blessé) ${ }^{52}$

- ? Céphale déguisé?

Drachenkampf

-Thésée (Alcathoüs ${ }^{53}$ )

Scène du bain

- Thésée (Minos)

${ }^{49}$ GotTfried de Strasbourg, Op. cit., pp. 600-601.

5) GotTtried de STRASBourg, Op. cit., p. 610.

"GotTfried de Strasbourg, $O p$. cit., p. 607.

52 Herido por la flecha envenenada de Moroldo, Tristán llega a Irlanda, en busca de cura. Aquí oculta su identidad a Isolda bajo el pseudónimo de Tantris.

5.3 Habiendo prometido el rey Megareo otorgar la mano de su hija a quien diera muerte al león que hab́́a devorado a un hijo suyo. presentóse Alcátoe, y logró eliminar a la fiera, obteniendo la ofrecida recompensa. Esta historia resulta semejante a la de la lucha de Teseo contra el Minotauro y al episodio del enfrentamiento de Tristán contra el dragón del Anferguinân. 
$\begin{array}{ll}\text { Retour jusqu'au Minnetrank } & \text { - Thésée } \\ \text { Depuis là retour } & \text { - Oenone } \\ & 54-\text { Hippolyte» (3959.8.1v) }\end{array}$

De nuestra interpretación de los manuscritos podemos deducir que Saussure reconocía la existencia de ciertos elementos invariables en los mitos, que sin embargo, podían revestir formas distintas, según sean adaptados por tal o cual leyenda. Encontramos aquí implícito el pensamiento saussuriano acerca de la difusión de la leyenda o del mito. El lingüista suizo piensa que a diferencia del signo una leyenda o una figura mítica se compone de una serie de rasgos invariables, pero que pueden prestarse al cambio en el tiempo, son elementos invariables con combinación espontánea y libre de un estado de leyenda a otro (3959.10.18).

Más precisamente, hemos podido constatar del estudio de Saussure que algunos elementos míticos perviven en la leyenda de Tristán e Isolda pero bajo forma atenuada, de modo que episodios enteros quedan reducidos a unas cuantas palabras referidas inconscientemente por un personaje o por el narrador, a algún detalle casi accesorio de la escena, o a algún objeto del decorado. Estos restos probablemente denoten la transformación de los elementos míticos como consecuencia de su adaptación al gusto y mentalidad de la época. También podemos aplicar aquí la explicación que el propio Saussure atribuye a las transformaciones de la leyenda en general: a veces, con el paso del tiempo y como consecuencia de la transmisión oral y escrita, algunas aventuras o escenas primitivas pueden verse reducidas a meros accesorios u objetos, puesto que el receptor pierde una parte del contenido original del emisor. Se trata de una modalidad transformadora que podemos denominar reducción. En cualquier caso los elementos en los que dichos episodios se ven reducidos mantienen con éstos una relación metonímica o analógica (3958.6.49r):

À chaque instant, par défaut de mémoire $<$ de < prédécesseurs $>$ ou autrement, le poète qui ramasse la légende ne recueille pour telle ou telle scène que les accessoires au sens le plus propre thêatral; quand les acteurs ont quitté la scène il reste tel et tel objet, una fleur sur le plancher, une [ ] qui reste dans la mémoire, et qui dit plus ou moins ce qui s'est passé, mais qui, n'étant que partiel, laisse marge à [ (3959.3.2v).

${ }^{54}$ La fábula de Enone se proyecta tan sólo al final de la leyenda céltica. Enone-lsolda es abandonada por Paris- Tristán, quien se une a otra mujer extranjera, Helena-lsolda de las blancas manos (o de Arundel). Un día el héroe cae mortalemente herido en un combate y Enone-lsolda no llega a tiempo para curarle. Encontrándole sin vida, ella muere también. 
Bibliografía

APOLODORO (1985): Biblioteca, Madrid, Gredos.

MarinetTi, Anna y Meli, Marcello (1986): Ferdinand de Saussure. Le leggende germaniche, Este, Zielo.

Ovidio (1994): Heroidas, Madrid, Alianza Editorial.

Ovidio (1996): Metamorfosis, Madrid, Alianza Editorial.

SAussure, Ferdinand: Notes et brouillons sur les Nibelungen. (suite). Tristan, Ms. fr.

3958 y Ms. fr. 3959, Bibliothèque Publique et Universitaire de Genève.

(1995): Tristan et Yseut. Les premières versions européennes, Gallimard. 